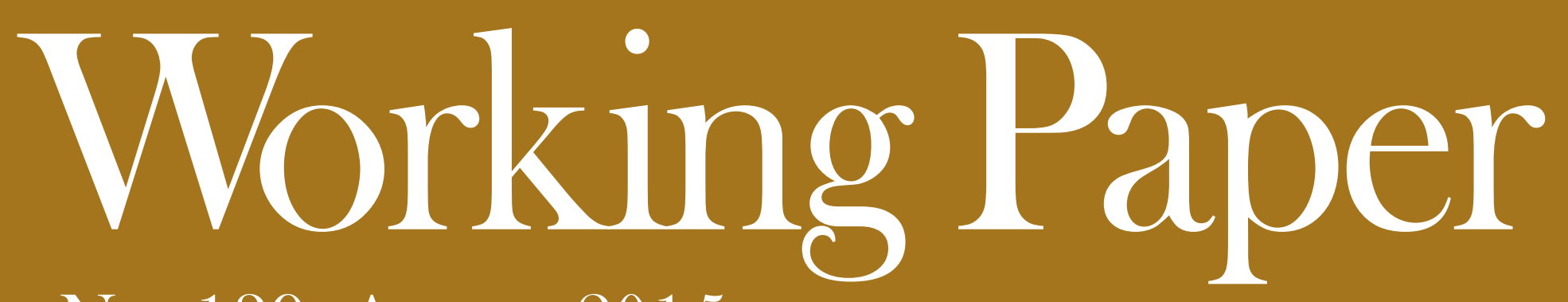

No. 139. August 2015

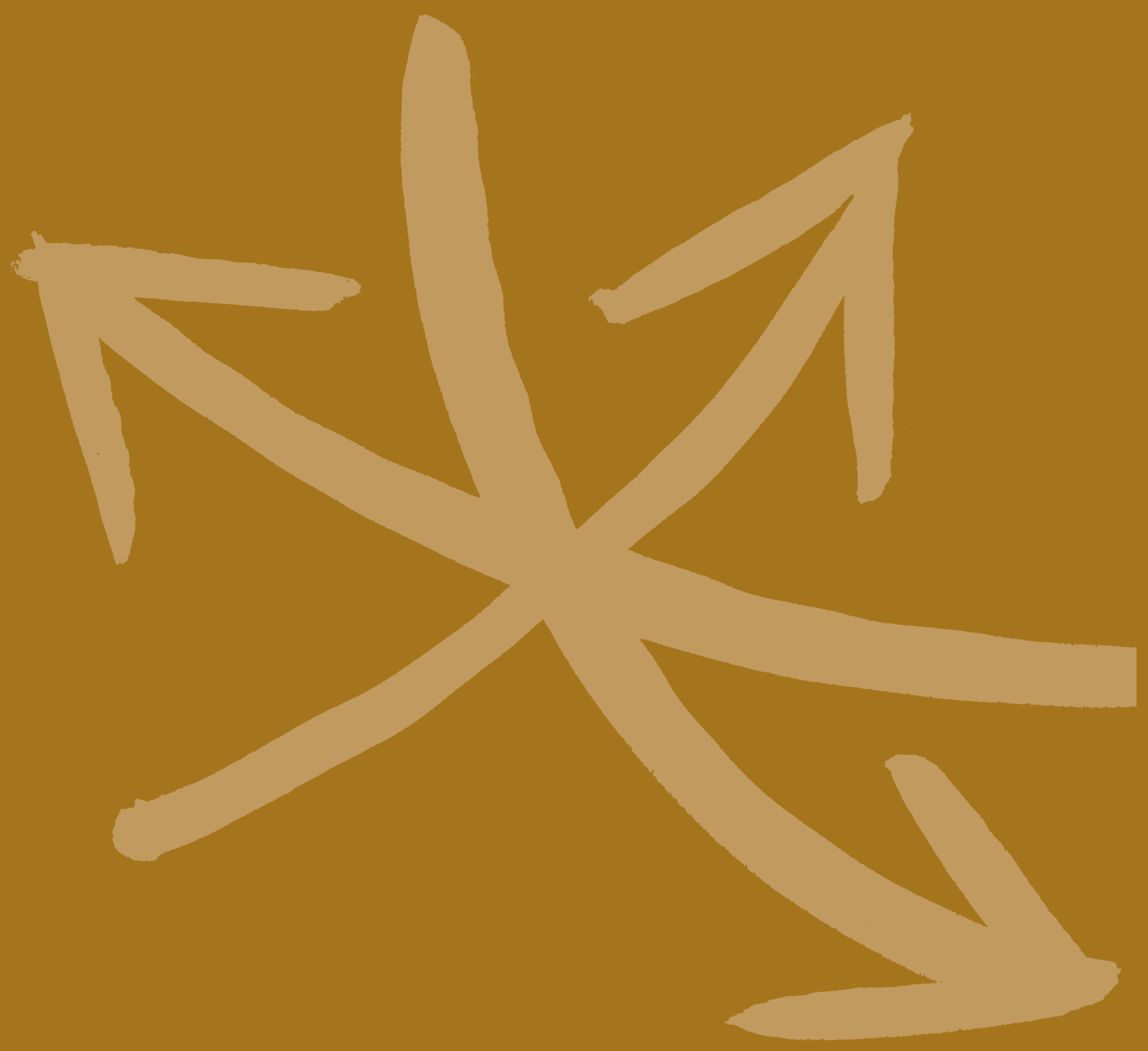

Do Swedish Consumer Confidence Indicators Do What They Are Intended to Do?

By Bengt Assarsson and Pär Österholm

National Institute of Economic Research

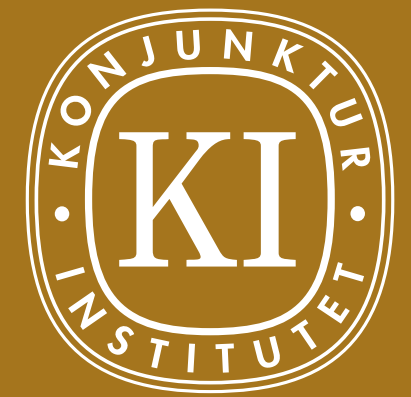





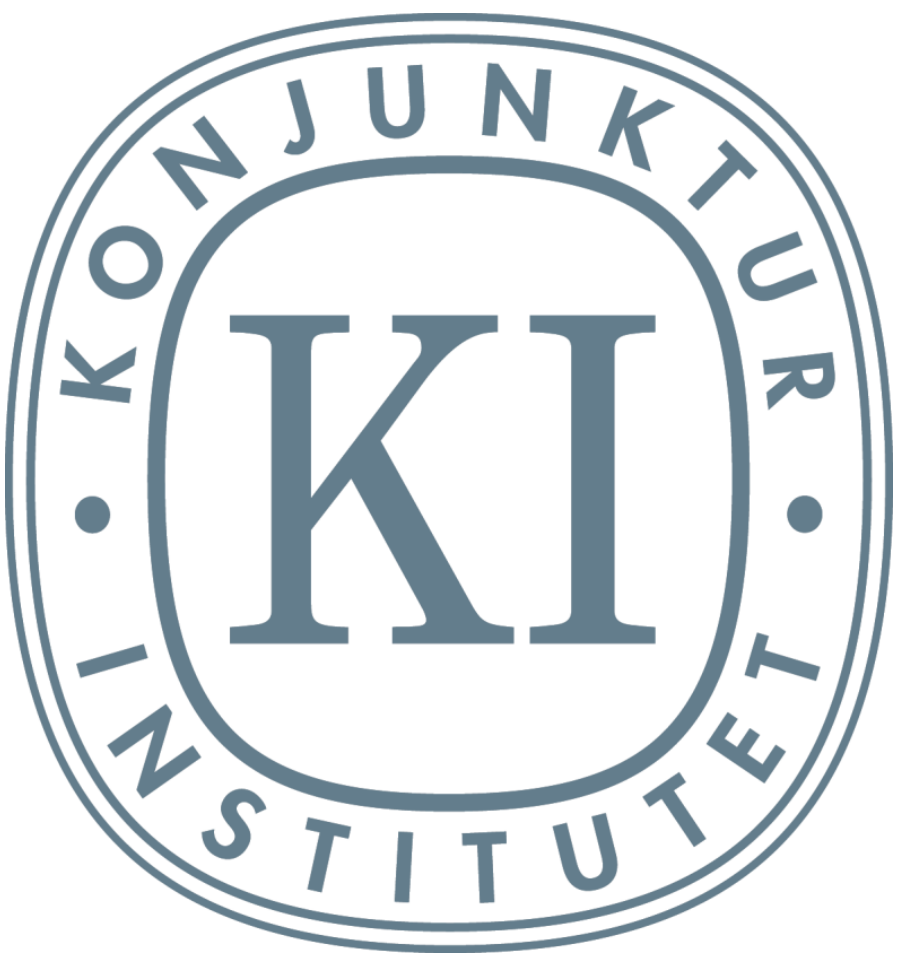

\section{Do Swedish Consumer Confidence Indicators Do What They Are Intended to Do?*}

Bengt Assarsson" and Pär Österholm*

August 2015

\footnotetext{
* We are grateful to Göran Hjelm and an anonymous referee for valuable comments on this paper.

\# National Institute of Economic Research, Box 3116, 10362 Stockholm, Sweden e-mail: bengt.assarsson@konj.se Phone: +46 84535922

* National Institute of Economic Research, Box 3116, 10362 Stockholm, Sweden e-mail: par.osterholm@konj.se Phone: +46 84535948
} 
NIER prepares analyses and forecasts of the Swedish and international economy and conducts related research. NIER is a government agency accountable to the Ministry of Finance and is financed largely by Swedish government funds. Like other government agencies, NIER has an independent status and is responsible for the assessments that it publishes.

The Working Paper series consists of publications of research reports and other detailed analyses. The reports may concern macroeconomic issues related to the forecasts of the institute, research in environmental economics, or problems of economic and statistical methods. Some of these reports are published in their final form in this series, whereas others are previews of articles that are subsequently published in international scholarly journals under the heading of Reprints.

Reports in both of these series can be ordered free of charge. Most publications can also be downloaded directly from the NIER website. 


\begin{abstract}
In this paper, we investigate whether the two main consumer confidence indicators available for Sweden - that of the National Institute of Economic Research and that of the European Commission - can nowcast Swedish household consumption expenditure. In a simulated out-ofsample nowcast exercise, we find that the consumer confidence indicator of the National Institute of Economic Research appears most useful for this purpose. The root mean square error of the nowcast from the model employing this indicator is the lowest of all the studied models which rely on survey data. The nowcasting performance of the model using the consumer confidence indicator of the European Commission is less impressive; while it outperforms the simplest possible benchmark model, its root mean square error is considerably higher than that of the model relying on the consumer confidence indicator of the National Institute of Economic Research. An implication of our findings is that while the European Commission's survey programme may have been successful in creating a set of harmonised data for the member countries of the European Union, it is not obvious that the harmonised indicators are the most relevant ones for analysis, nowcasting or forecasting in each country.
\end{abstract}

JEL classification code: E21, E27

Keywords: Household consumption, Nowcasting 


\section{Sammanfattning}

I denna studie undersöks huruvide de två huvudsakliga konsumentförtroendeindikatorerna i Sverige - Konjunkturinstitutets och Europeiska kommissionens - kan prognostisera utvecklingen i hushållens konsumtionsutgifter för innevarande kvartal. Vi genomför en simulerad prognosövning som visar att Konjunkturinstitutets indikator förefaller mest användbar i detta syfte. Rotmedelkvadratfelet för den modell som använder denna indikator är lägst av alla studerade modeller som använder enkätdata. Prognosförmågan hos modellen som använder Europeiska kommissionens indikator är mindre imponerande; den är förvisso bättre än den enklaste jämförelsemodellen men rotmedelkvadratfelet är avsevärt högre än för modellen som använder Konkjunkturinstitutets indikator. En implikation av våra resultat är att Europeiska kommissionens program för enkätdata må ha varit framgångsrikt när det gäller att skapa harmoniserade data för medlemsländerna i Europeiska unionen, men det är inte uppenbart att dessa harmoniserade indikatorer är de mest relevanta för analys- eller prognosarbete rörande respektive land. 


\section{Introduction}

In most countries, the results from consumer confidence surveys are typically discussed in mass media when they are released and it is obviously assumed that they provide some important economic information. This seems reasonable - even if results are somewhat mixed, there is a fair amount of evidence that consumer confidence is relevant for modelling and forecasting household consumption expenditure; see, for example, Carroll et al. (1994), Ludvigson (2004), Easaw et al. (2005), Cotsomitis and Kwan (2006), Kwan and Cotsomitis (2006) and Dreger and Kholodilin (2013). However, evidence on the relevance of consumer confidence for consumer spending is available for a limited number of countries and varies depending on how the surveys are designed, estimation procedures, data, etcetera. Since policy makers, consumers, businesses and other economic decision makers extensively use these indicators to get a better perception of the state of the economy it is important to analyse the performance of different indicators.

The purpose of this paper is to investigate whether the two main consumer confidence indicators available for Sweden - that of the National Institute of Economic Research (NIER) and that of the European Commission - help in nowcasting Swedish aggregate household consumer spending. ${ }^{1}$ We thereby add to the literature in two ways. First, we shed light on the informational value of consumer confidence indicators for the Swedish economy. Focus is put on the ability to predict the outcome of the present quarter when standing partway through it, that is, the ability to nowcast. Given that the NIER points out that its consumer confidence indicator has been designed to "obtain the greatest possible correlation with a particular reference series" (National Institute of Economic Research, 2013, p. 14), nowcasting ability seems like a reasonable property to evaluate. If the NIER has been successful in its task, its consumer confidence indicator should be useful when nowcasting household consumption. In addition to investigating the nowcasting performance of the two consumer confidence indicators, we also study whether other variables possibly would do the job better. We assess this by also using a number of variables based on data from the NIER's Economic Tendency Survey, including individual questions in the household section of the sur-

\footnotetext{
1 Some research has shown that sentiment indicators are particularly valuable for predicting consumption components, for example durables; see Easaw et al. (2013). In this paper, however, we focus on aggregate consumption only.
} 
vey. ${ }^{2}$ Second, by making a comparison between the nowcasting performance of the NIER's country specific indicator and the European Commission's standardised indicator, we provide information concerning the general usefulness of the European Commission's standardised indicator. ${ }^{3}$ In order to establish, for example, what conclusions can actually be drawn from cross-country comparisons based on the European Commission's indicator, we first need knowledge about the properties of different indicators.

The rest of this paper is organised as follows: In Section 2, we describe the data used in the analysis. The estimated models and our results are presented in Section 3. Finally, Section 4 concludes.

\section{Data}

We use data from the NIER and the European Commission. The consumer confidence indicator of the NIER - henceforth denoted "CCI-NIER" - is constructed by taking the mean of seasonally adjusted and standardised net figures from five questions of the Economic Tendency Survey; 4 the indicator is finally standardised to have a mean of 100 and a standard deviation of 10. The European Commission's Directorate General for Economic and Financial Affairs provides harmonised survey results for the member countries of the EU in a number of areas. Here we employ its consumer confidence indicator, henceforth denoted "CCI-EC"; this is constructed by taking the mean of seasonally adjusted net figures (in percentage points) of four different questions in the NIER's Economic Tendency Survey.5

Apart from the two consumer confidence indicators, we also employ net figures from individual questions in the Economic Tendency Survey, as well as two alternative indices of household confidence calculated by the NIER - the "Micro index" and the "Macro

\footnotetext{
2 See National Institute of Economic Research (2013) for a complete user guide to the survey. See Appendix A in this paper for a detailed list of the questions._It can be noted that data from the Economic Tendency Survey has been shown to have predictive power for the real economy in a number of studies; see, for example, Hansson et al. (2005) and Österholm (2014).

3 It can be noted that the NIER's Economic Tendency Survey is the source of both consumer confidence indicators; the difference between them is how the questions are weighted together, seasonally adjusted and standardised.

${ }^{4}$ Specifically, it is questions $1,2,3,4$ and 9 that are used (see Appendix A).

5 Specifically, it is questions 2, 4, 7 and 11 that are used (see Appendix A).
} 
index" - and an index constructed so as to "ensure a high degree of correlation with GDP growth" (National Institute of Economic Research, 2013, p. 18), the "Economic Tendency Indicator”. By also studying these data, we can assess the possible success anticipated for the consumer confidence indicators; it would seem reasonable that other easily available information should not be more useful for nowcasting household consumption than the consumer confidence indicators.

Turning to the data on household consumption, we use quarterly real-time data on seasonally adjusted household consumption expenditure in fixed prices from the national accounts. These data have been retrieved from the historical data banks of the NIER.

Concerning the real-time data aspect, it can be noted that real-time data on CCINIER, the Micro index, the Macro index and the Economic Tendency Indicator are not available and due to the construction of the variables, the present vintage is not equal to real-time data. While the CCI-EC is seasonally adjusted, its history is not revised. Therefore the present vintage of this time series is equivalent to real-time data. Finally, net figures from the individual questions in the Economic Tendency Survey have not been seasonally adjusted and since they are not revised, this means that these times series are also equivalent to real-time data. ${ }^{7}$

All data except question 16 span the period 1996Q3-2014Q2. The time series for question 16 starts in 2001Q3. Data on household consumption, CCI-NIER, CCI-EC and the Economic Tendency Indicator are shown in Figure $1 .{ }^{8}$ From the two panels it seems that the CCI-NIER and the Economic Tendency Indicator are more closely related to household consumption growth than the CCI-EC is.

\footnotetext{
${ }^{6}$ The Micro index uses questions 1, 2, 8 and 9. The Macro index uses questions 3, 4 and 7 (see Appendix A).

7 Our results should not be seriously affected by the fact that we cannot conduct a proper real-time data analysis for all variables. Analysis using the individual questions in the Economic Tendency Survey indicates that results are both qualitatively and quantitatively very similar when using seasonally adjusted data instead of the original data. (Results are not reported but are available from the authors upon request.)

8 It should be noted that the data on household consumption shown in Figure 1 are the vintage published in August 2014. For our empirical analysis, 43 different vintages of data on household consumption are used.
} 


\section{Figure 1. Data.}

Percent

Indicator value

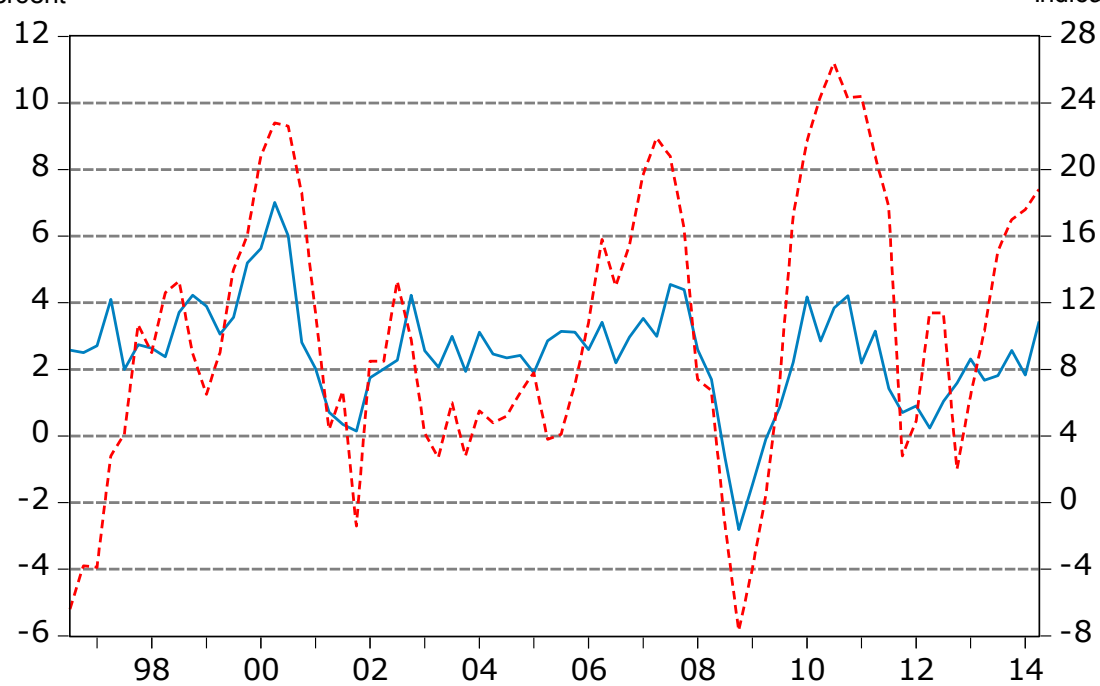

- Household consumption [left axis]

---- Household confidence (EC) [right axis]

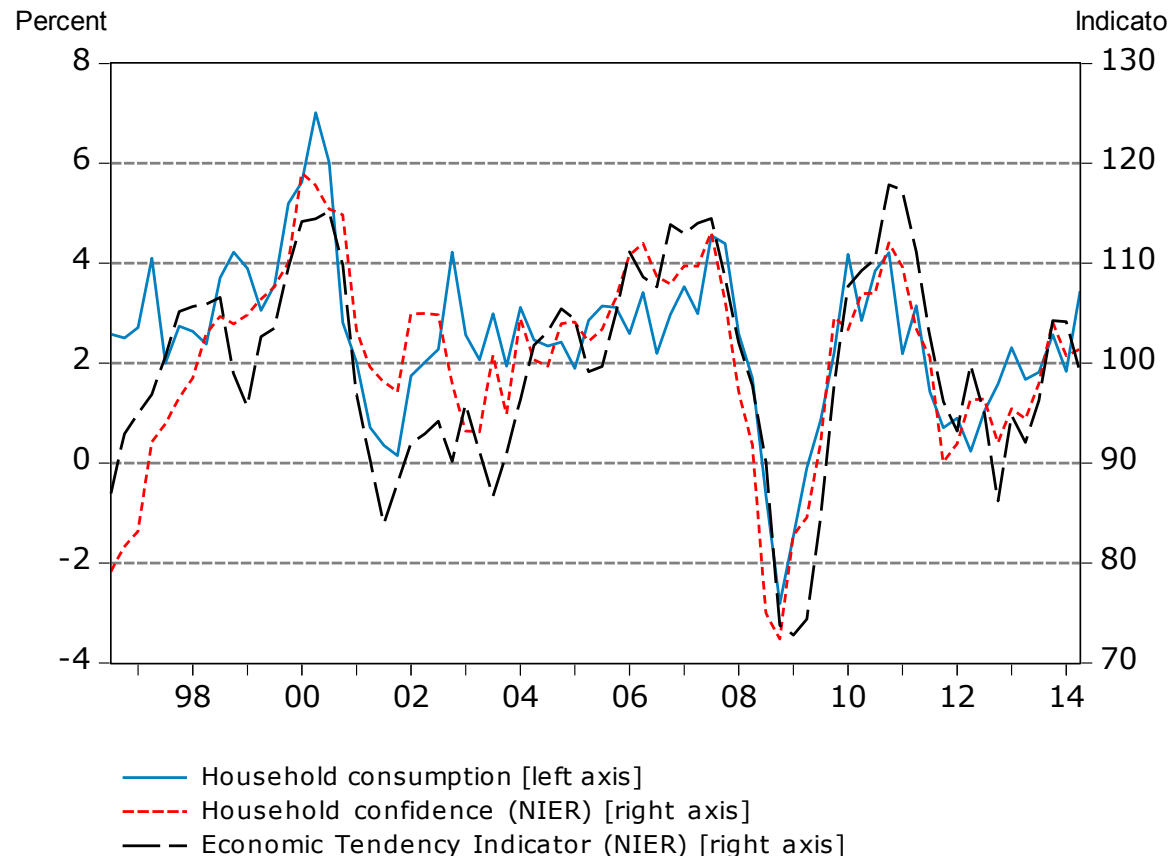

Note: Household consumption is measured as the year-on-year percentage change in seasonally adjusted household consumption expenditure in fixed prices and is given on the left axis in both panels; vintage of data published in July 2014. Household confidence indicators and the Economic Tendency Indicator are given on the right axis.

\section{Empirical analysis}

We conduct a simulated out-of-sample nowcast exercise using a number of simple models. The first nowcast uses data on household consumption from 1996Q3 to 
2003Q4. This corresponds to national accounts data which would have been released in late February 2004. The survey data that would have been available for nowcasting at this point in time corresponds to the Economic Tendency Survey published in February 2004. Using these data, each estimated model generates a nowcast for 2004Q1. The sample is then expanded one quarter and new nowcasts are generated, and so forth. ${ }^{9}$ The final nowcast is based on data on household consumption from 1996Q3 to 2014Q1 and it is the nowcasts for 2014Q2 which are evaluated. In total, we evaluate 42 nowcasts for each estimated model.

\subsection{Estimated models}

Four simple alternative models are estimated to provide reference points. First, we use a model with only a constant:

$g_{t}=c+e_{t}$

where $g_{t}=\left(H_{t}-H_{t-4}\right) / H_{t-4}, e_{t}$ is an error term and $H_{t}$ is household consumption in period $t .10$ Outperforming this model will be the requirement for a model to have "nowcast content"; 11 if a model cannot beat the model which simply says that the growth rate will be the (estimated) historical average, it should have little value to a nowcaster.

Since we are relying on year-on-year changes but analyse data on a quarterly frequency, $g_{t}$ will have an MA(3) structure. We therefore also estimate an MA(3) model

$g_{t}=c+\theta_{1} e_{t-1}+\theta_{2} e_{t-2}+\theta_{3} e_{t-3}+e_{t}$

\footnotetext{
${ }^{9}$ We hence assume that nowcasts for the quarter in question are generated shortly after the national accounts data for the previous quarter are released; this is indeed how several forecasters in Sweden work, including the NIER. The survey data are monthly and we use the most recent month available for our nowcasting models; accordingly, the values from the February survey are used when nowcasting the first quarter, May is used for the second quarter, July for the third quarter (since national accounts data for the second quarter are released with a shorter delay) and November for the fourth quarter. This is a highly reasonable choice even if the predictive power may differ between the months of the quarter; see, for example, Dreger and Kholodilin (2013).

10 While a model with only a constant might seem overly simplistic, it is not an unreasonable model if household consumption is a random walk (with drift), a standpoint which has some theoretical support; see, for example, Hall (1978). However, if household consumption is a random walk (with drift), this would imply that it is the quarter-on-quarter change in household consumption which should be modelled according to equation (1), not the year-on-year change.

11 Assessing the nowcast content based on the performance of a model relative to that of the historical average is in line with Galbraith (2003). Outperforming (in RMSE terms) the forecast provided by the unconditional average is also the criterion used by Andersson (2000) to establish "forecast memory".
} 
as an alternative simple model. In addition, we also include an $\mathrm{AR}(1)$ model,

$g_{t}=c+\rho g_{t-1}+e_{t}$

since it is a commonly employed benchmark model in applied macroeconomics; see, for example, Mitchell (2009) or Pesaran et al. (2009). Due to the MA(3) structure mentioned above, it is not unreasonable though to allow for more dynamics and we, finally, therefore also include an AR(2) model in our suite of benchmark models.

$g_{t}=c+\rho_{1} g_{t-1}+\rho_{2} g_{t-2}+e_{t}$

We then estimate models based on survey data. Each has the form

$g_{t}=c+b S_{t}+e_{t}$

where $S_{t}$ is a variable based on survey data.

\subsection{Results}

The root mean square error (RMSE) of the nowcast is used as the evaluation criterion. This is calculated as

$R M S E=\sqrt{(1 / n) \sum_{i=0}^{n-1}\left(v_{t+i \mid t+i}\right)^{2}}$

where $v_{t+i \mid t+i}=g_{t+i}-\hat{g}_{t+i \mid t+i}$, where $v_{t+i \mid t+i}$ is the nowcast error, $g_{t+i}$ the outcome and $\hat{g}_{t+i \mid t+i}$ the nowcast of household consumption growth at time $t+i$ made at time $t+i$.

As can be seen from Table 1, and Table A1 in Appendix B, the best benchmark model is equation (2) with an RMSE of 0.92. This is the MA(3) model. Concerning the models relying on survey data, they all have nowcast content since their RMSEs are lower than that of the model with only a constant [equation (1)]. The best performance is found for the CCI-NIER and Micro index with an RMSE of 0.93. The CCI- 
EC has an RMSE of 1.60 which is substantially worse. The CCI-NIER accordingly does a better job in nowcasting household consumption than the CCI-EC does. The fact that the CCI-NIER generates the lowest RMSE of all variables based on survey data is also an appealing finding; it seems that there is indeed some relevant information in this indicator. It is worth noting though that not even the model relying on the CCI-NIER outperforms the best benchmark model. This does, however, not mean that the survey data are irrelevant to nowcasters. As was pointed out above, the models based on survey data all have nowcast content and this is the most relevant criterion to assess. It should also be kept in mind that we are using simple models for our evaluation. Survey data might, however, also be useful for the nowcaster when making a more complex model (when aiming to build the "best possible" nowcasting model).12

Table 1. Root mean square nowcast errors for the annual percentage change in household consumption and GDP.

\begin{tabular}{|c|c|c|c|c|}
\hline & \multicolumn{2}{|c|}{$\begin{array}{l}\text { Household } \\
\text { consumption }\end{array}$} & \multicolumn{2}{|c|}{ GDP } \\
\hline & $\begin{array}{l}\text { Reference } \\
\text { models }\end{array}$ & $\begin{array}{c}\text { Equation } \\
\text { (5) }\end{array}$ & $\begin{array}{l}\text { Reference } \\
\text { models }\end{array}$ & $\begin{array}{c}\text { Equation } \\
\text { (5) }\end{array}$ \\
\hline Constant [Equation (1)] & 1.76 & - & 3.22 & - \\
\hline MA(3) [Equation (2)] & 0.92 & - & 1.53 & - \\
\hline$A R(1)$ [Equation (3)] & 1.05 & - & 1.68 & - \\
\hline $\operatorname{AR}(2)$ [Equation (4)] & 0.98 & - & 1.56 & - \\
\hline CCI-NIER & - & 0.93 & - & 2.21 \\
\hline Micro & - & 0.93 & - & 2.44 \\
\hline Macro & - & 1.22 & - & 2.25 \\
\hline Economic Tendency Indicator & - & 1.27 & - & 1.91 \\
\hline CCI-EC & - & 1.60 & - & 2.65 \\
\hline
\end{tabular}

From Table A1, it can also be seen that question 3 has the highest nowcast precision of the individual questions with an RMSE of 1.13. This is the question "How do you think the general economic situation in this country has changed over the last 12 months?". This question is included in the CCI-NIER but not in the CCI-EC. The second lowest RMSE of the individual questions is that of question 9; its RMSE is 1.14. Again, this is

\footnotetext{
12 As a simple example, consider the case where survey data are added to equation (4) so that the equation $g_{t}=c+\rho_{1} g_{t-1}+\rho_{2} g_{t-2}+b S_{t}+e_{t}$ is estimated. In this case, the RMSE when using the CCI-NIER is 0.75 which is a fair bit lower than the RMSE of the MA(3) model in equation (2). If the CCI-EC is used similarly, the RMSE is 1.03 .
} 
a question included in CCI-NIER but not in CCI-EC. Looking further into the composition of these two indices, it can be noted that the questions 7 and 11 are included in the CCI-EC but not in CCI-NIER. As can be seen from Table A1, question 7 has an RMSE of 1.32 which makes it the fourth best individual question. The RMSE of question 11 is a moderately impressive 1.68. It can be concluded that the choice of questions in the consumer confidence indicator is important ${ }^{13}$ and it seems that the NIER has been more successful than the European Commission in this task considering the results from our out-of-sample nowcast exercise. ${ }^{14}$

As the final part of our empirical analysis, we also conduct the same analysis as above but instead use GDP growth as the dependent variable. This can give us some insight concerning whether the CCI-NIER is a good macroeconomic indicator in general or if its merits specifically lie in the area of household consumption. As can be seen from Table 1, the model using the Economic Tendency Indicator now outperforms all other models relying on survey data. Again, the CCI-NIER performs better than the CCIEC but its RMSE is fairly large relative to the benchmark models'. But while it has nowcast content, the CCI-NIER cannot be judged very successful in nowcasting GDP growth. Our results are reassuring though since the intention with the CCINIER and Economic Tendency Indicator is to ensure a high correlation with household consumption growth and GDP growth, respectively.

\section{Conclusions}

Forecasting or nowcasting macroeconomic time series using simple time series models or sophisticated macroeconometric models is difficult and the errors are often disappointingly large. Most forecasting institutions concentrate on short- and medium-term forecasts (up to about two years ahead). Having a good starting point then seems important. This can be attained with accurate nowcasts, where appropriate indicators could be used for this purpose.

In this paper we have investigated whether survey data can help when nowcasting household consumption in Sweden. In particular, we compared the performance of

13 This has previously also been shown by Bram and Ludvigson (1998) for US data.

14 It should be noted though that it need not be optimal to choose the individual questions associated with the highest nowcast precision for the consumer confidence indicator. The optimal questions to include - from a nowcasting perspective - also depends on the covariances of the nowcast errors from the different models. 
the consumer confidence indicators used by the NIER and the European Commission, which both use different questions from the NIER's Economic Tendency Survey. As benchmark models we use some simple time series specifications. Our results show that both consumer confidence indicators have nowcast content - that is, the models which rely upon them outperform the nowcast that says that the growth rate of household consumption will be the historical average. The indicators accordingly have informational value to analysts and forecasters and we hence conclude that they do what they are supposed to do, even if the models based on the indicators do not necessarily outperform all of the simple benchmark models.

In addition, our results indicate that the NIER's consumer confidence indicator outperforms that of the European Commission. The differences between the two consumer confidence indicators are non-negligible. This shows that the choice of questions included in the consumer confidence indicator matters empirically and that the informational value of the NIER's consumer confidence indicator appears larger than that of the European Commission. Our results hence imply that while the European Commission's survey programme may have been successful in creating a set of comparable data for the member countries of the European Union, it is not obvious that the harmonised indicators are the most relevant ones for analysis, nowcasting or forecasting in each country. This does not mean that we advocate that changes should be made to the European Commission's national consumer confidence indicators - there is after all a value to having harmonised indicators. It does, however, imply that one should think about what conclusions can actually be drawn from cross-country comparisons based on the European Commission's indicator. In addition, our findings imply that those who nowcast or forecast household consumption for different countries of the European Union most likely have to look beyond the European Commission's harmonised indicator for the respective country in order to find the variables that are most productive. 


\section{References}

Andersson, M. K. (2000), “Do Long-Memory Models Have Long Memory?”, International Journal of Forecasting 16, 121-124.

Bram, J. and Ludvigson, S. (1998), "Does Consumer Confidence Forecast Household Expenditure? A Sentiment Index Horse Race", Federal Reserve Bank of New York Economic Policy Review, 4, 59-78.

Carroll, C. D., Fuhrer, J. C. and Wilcox, D. W. (1994), "Does Consumer Sentiment Forecast Household Spending? If So, Why?”, American Economic Review 84, 13971408.

Cotsomitis, J. A. and Kwan, A. C. C. (2006), "Can Consumer Confidence Forecast Forecast Household Spending? Evidence from the European Commission Business and Consumer Surveys", Southern Economic Journal 72, 597-610.

Croushore, D. and Stark, T. (2001), "A Real-Time Data Set for Macroeconomists", Journal of Econometrics 105, 111-130.

Dreger, C. and Kholodilin, K. A. (2013), "Forecasting Private Consumption by Consumer Surveys", Journal of Forecasting 32, 10-18.

Easaw, J. Z., Garratt, D. and Heravi, S. M., (2005), “Does Consumer Sentiment Accurately Forecast UK Household Consumption? Are there any Comparisons to be Made with the US?", Journal of Macroeconomics 27, 517-532.

European Commission (2014), The Joint Harmonised EU Programme of Business and Consumer Surveys.

Galbraith, J. W. (2003) "Content Horizons for Univariate Time Series Forecasts", International Journal of Forecasting 19, 43-55.

Hall, R. E. (1978), "The Stochastic Implications of the Life Cycle-Permanent Income Hypothesis: Theory and Evidence”, Journal of Political Economy 86, 971-987.

Hansson, J., Jansson, P. and Löf, M. (2005), "Business Survey Data: Do They Help in Forecasting GDP Growth?”, International Journal of Forecasting 21, 377-389.

Kwan, A. C. C. and Cotsomitis, J. A. (2006), "The Usefulness of Consumer Confidence in Forecasting Household Spending in Canada: A National and Regional Analysis", Economic Inquiry 44, 185-197.

Ludvigson, S. (2004), "Consumer Confidence and Consumer Spending", Journal of Economic Perspectives 18, 29-50.

Mitchell, J. (2009), "Where Are We Now? The UK Recession and Nowcasting GDP Growth Using Statistical Models", National Institute Economic Review 209, 60-69.

National Institute of Economic Research (2013), User Guide to the Economic Tendency Survey. $\quad$ http://www.konj.se/download/18.2cabf50a141002857ee147b/UserGuide-Economic-Tendency-Survey.pdf 
Österholm, P. (2014), "Survey Data and Short-Term Forecasts of Swedish GDP Growth", Applied Economics Letters 21, 135-139.

Pesaran, M. H., Schuermann, T. and Smith, L. V. (2009), "Forecasting Economic and Financial Variables with Global VARs", International Journal of Forecasting 25, 642675. 


\section{Appendix A - Questions in the NIER's Economic Tendency Survey evaluated in this study}

1. How does the financial situation of your household now compare with what it was 12 months ago? Has it...?

Got a lot better

Got a little better

Stayed the same

Got a little worse

Got a lot worse

Don't know

2. How do you think the financial position of your household will change over the next 12 months? Will it...?

Get a lot better

Get a little better

Stay the same

Get a little worse

Get a lot worse

Don't know

3. How do you think the general economic situation in this country has changed over the last 12 months? Has it...?

Got a lot better

Got a little better

Stayed the same

Got a little worse

Got a lot worse

Don't know

4. How do you think the general economic situation in this country will develop over the next 12 months? Will it...?

Get a lot better

Get a little better

Stay the same

Get a little worse

Get a lot worse

Don't know 
5. Compared with 12 months ago, do you find that prices in general are...?

Very much higher

Quite a bit higher

A little higher

About the same

Lower

Don't know

5c. Compared with 12 months ago, how much higher in percent do you think that prices are now?

6. Compared to the situation today, do you think that at in the next 12 months prices in general will...?

Increase faster

Increase at the same rate

Increase at a slower rate

Stay about the same

Fall slightly

Don't know

6c. Compared with today, how much in percent do you think that prices will go up (i.e. the rate of inflation 12 months from now)?

7. How do you think the level of unemployment in the country will change over the next 12 months? Will it...?
Increase sharply
Increase slightly
Remain the same
Fall slightly
Fall sharply
Don't know

8. Do you think there is an advantage for people to make major purchases (furniture, washing machines, TV sets etc.) at the present time?

Yes, now is the right time

It is neither the right time nor the wrong time

No, it is the wrong time, purchase should be postponed

Don't know 
9. Over the next 12 months, how do you think the amount of money you will spend on major purchases will compare with what you spent over the last 12 months? Will it be...?

Much more

A little more

About the same

A little less

Much less

Don't know

10. In the view of the general economic situation, do you think this is...?

A very good time to save

Quite a good time to save

Neither a good, nor an unfavourable time to save

Rather an unfavourable time to save

A very unfavourable time to save

Don't know

11. Over the next 12 months, how likely are you to be able to save any money?

Very likely

Fairly likely

Fairly unlikely

Very unlikely

Don't know

12. Which of these statements best describe the present financial situation of your household?

We are saving a lot

We are saving a little

We are just managing to make ends meet on our income

We have to draw on our savings

We are running into debt

Don't know

13. How likely are you to buy a car within the next 12 months?

Very likely

Fairly likely

Fairly unlikely

Very unlikely

Don't know 
14. Are you planning to purchase or build a home within the next 12 months (to live in yourself, for a member of your family, as a holiday home, to let etc.)?
Yes, definitely
Possibly
Probably not
Definitely not
Don't know

15. Over the next 12 months, how likely are you to spend any large sums of money on home improvements such as central heating, sanitary ware etc.?

Very likely

Fairly likely

Fairly unlikely

Very unlikely

Don't know

16. Compared with 12 months ago, is the risk that you will become unemployed...?
A lot greater
A little greater
About the same
A little less
A lot less
No opinion 


\section{Appendix B - Root mean square errors}

Table A1. Root mean square errors for the annual percentage change in household consumption.

\begin{tabular}{|c|c|c|}
\hline & $\begin{array}{l}\text { Reference } \\
\text { models }\end{array}$ & $\begin{array}{c}\text { Equation } \\
\text { (5) }\end{array}$ \\
\hline Constant [Equation (1)] & 1.76 & - \\
\hline MA(3) [Equation (2)] & 0.92 & - \\
\hline$A R(1)$ [Equation (3)] & 1.05 & - \\
\hline $\operatorname{AR}(2)$ [Equation (4)] & 0.98 & - \\
\hline 1 & - & 1.45 \\
\hline 2 & - & 1.24 \\
\hline 3 & - & 1.13 \\
\hline 4 & - & 1.78 \\
\hline 5 & - & 1.72 \\
\hline $5 c$ & - & 1.63 \\
\hline 6 & - & 1.50 \\
\hline $6 c$ & - & 1.84 \\
\hline 7 & - & 1.32 \\
\hline 8 & - & 1.44 \\
\hline 9 & - & 1.14 \\
\hline 10 & - & 1.84 \\
\hline 11 & - & 1.68 \\
\hline 12 & - & 1.83 \\
\hline 13 & - & 1.54 \\
\hline 14 & - & 1.60 \\
\hline 15 & - & 1.78 \\
\hline 16 & - & 1.37 \\
\hline CCI-NIER & - & 0.93 \\
\hline Micro & - & 0.93 \\
\hline Macro & - & 1.22 \\
\hline Economic Tendency Indicator & - & 1.27 \\
\hline CCI-EC & - & 1.60 \\
\hline
\end{tabular}

Note: The numbers in the far left column refer to the number a specific question has in the Economic Tencency Survey (see Appendix A). 



\section{National Institute of Economic Research, Kungsgatan 12-14, Box 3116, SE-103 62 Stockholm, Sweden}

+4684535900, info@konj.se, www.konj.se/en

\section{ISSN 1100-7818}

